\title{
Mechanochemistry of Cardiac Muscle
}

\section{INFLUENCE OF THYROID STATE ON ENERGY}

\author{
UTILIZATION
}

\author{
C. Lynn Skelton, Peter E. Pool, Shirley C. Seagren, and \\ Eugene Braunwald
}

From the Cardiology Branch, National Heart and Lung Institute, Bethesda, Maryland 20014, and the Department of Medicine, University of California at San Diego, La Jolla, California 92037

\begin{abstract}
A в S T RACT The possibility that alterations in the rate or efficiency of energy utilization could be involved in the control of cellular oxygen consumption by thyroid hormone was examined in right ventricular papillary muscles isolated from normal euthyroid cats and cats with experimentally induced hyperthyroidism and hypothyroidism. Energy production in the muscles was inhibited and isolated from the process of energy utilization by exposure to iodoacetic acid and nitrogen. After resting or performing variable amounts of contractile element work under isometric conditions, muscles were frozen, and the total amount of chemical energy $(\sim P=$ creatine phosphate + ATP) used was determined. The resting rate of energy utilization in muscles from euthyroid animals was $0.78 \pm 0.07 \mu$ moles $/ g$ per min of $\sim P$. This rate was elevated in muscles from hyperthyroid cats to $1.00 \pm 0.09 \mu$ moles $/ \mathrm{g}$ per min and decreased in muscles from hypothyroid cats to $0.23 \pm 0.14 \mu \mathrm{moles} / \mathrm{g}$ per min. Isometrically contracting muscles from cats with hypothyroidism utilized only $64 \%$ as much energy as muscles from euthyroid cats while performing $81 \%$ as much contractile element work at a moderately decreased level of contractile state. Muscles from hyperthyroid cats utilized an average of $41 \%$ more energy than did muscles from euthyroid cats while contracting an identical number of times and performing an equal
\end{abstract}

Presented in part before The American Society for Clinical Investigation, Atlantic City, N. J., 6 May 1968. (1968. J. Clin. Invest. 47: 80a. [Abstr.], and The American Physiological Society, Davis, Calif., 26 August 1969. (1969. Physiologist. 12: 353.)

Dr. Skelton's present address is Cardiovascular Division, Peter Bent Brigham Hospital, Harvard Medical School, Boston, Mass. 02115.

Received for publication 5 June 1970 and in revised form 16 September 1970. amount of contractile element work at a slightly increased level of contractile state. These results suggest that thyroid hormone directly influences the rate of cellular energy utilization. Furthermore, the increase in energy utilization in muscles from hyperthyroid cats could not be attributed entirely to observed alterations in contractile behavior, which indicates that excess thyroid hormone may decrease the efficiency of the conversion of cellular energy to work. However, the opposite effect, an increased efficiency of energy utilization, was not observed in muscles from hypothyroid cats. Thus, it is concluded that the calorigenic effects of thyroid hormone may be explained, at least in part, by alterations in the process of energy utilization.

\section{INTRODUCTION}

Thyroid hormone has many effects on cellular function, the most striking of which is its influence on oxygen consumption or energy metabolism. The stimulation of oxygen consumption found in most tissues after the administration of thyroid hormone has been attributed to changes in the rate of energy generation, the efficiency of energy generation, or a combination of these (1). The chief features of clinical and experimental hyperthyroidism and hypothyroidism have been postulated to result from changes in the process of energy generation (2), shown schematically in Fig. 1 as Coupling A. However, it is also possible that a change in the rate or efficiency of energy utilization, Coupling B, could be an important determinant of the alterations in energy metabolism found in hyperthyroidism and hypothyroidism. In order to determine whether alterations in energy utilization are involved in the stimulation of cellular oxygen consumption by thyroid hormone, it is 


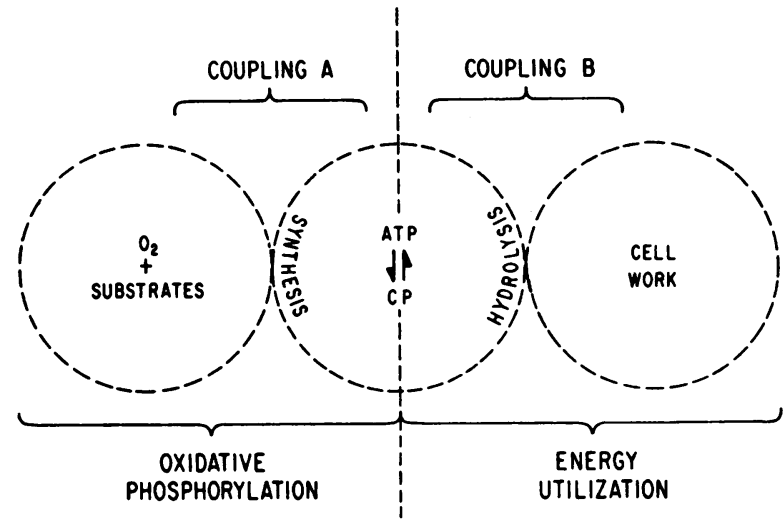

FIGURE 1 Schematic representation of those processes involved in the synthesis and degradation of high-energy phosphates (ATP + creatine phosphate) in the cell. Coupling A $=$ processes of energy generation; Coupling $\mathrm{B}=$ processes of energy utilization.

necessary to measure energy transformation under conditions where energy generation has been eliminated. Cardiac muscle has been found to be a convenient tissue for this purpose $(3,4)$.

Adenosine triphosphate (ATP) is thought to be the immediate energy source for muscle contraction (5). Creatine phosphate is in equilibrium with ATP, and together they provide the readily available energy supply for the heart. When cardiac muscle is exposed to an appropriate concentration of iodoacetic acid, anaerobic glycolysis is inhibited. In addition, if cardiac muscle is deprived of oxygen by placing it in an atmosphere of nitrogen, oxidative phosphorylation is also inhibited, and the result of the combination of these procedures is to inhibit completely the process of energy generation. Measurement of myocardial high-energy phosphate concentrations (ATP and creatine phosphate) under conditions in which no net synthesis of ATP or creatine phosphate can occur provides a means of directly assessing the rate of energy utilization in cardiac muscle under conditions of rest or activity.

Measurement of the basal rate of energy utilization in resting cardiac muscle is analogous to measurements made in tissues where the effects of thyroid hormone have been most thoroughly studied, e.g., liver. In liver and resting cardiac muscle, there is no readily available measure of the quantity of cellular work performed, information that is essential for determining the efficiency of cellular energy utilization. On the other hand, the contraction of cardiac muscle provides a form of cellular work where the extent of the process may be determined directly and correlated with energy utilization to provide an estimate of the efficiency of cellular energy utilization $(3,4)$.
The purpose of the present study was to determine the influence of alterations of thyroid state on the process of energy utilization. We used a cardiac muscle preparation, the cat right ventricular papillary muscle, because both the rate and efficiency of energy utilization can be readily determined in this preparation while permitting the direct demonstration of the effects of excess thyroid hormone or its deprivation on myocardial mechanical performance.

\section{METHODS}

Experimental preparation. Studies were performed using normal adult cats, cats made hyperthyroid by the intraperitoneal injection of 1-thyroxine $(0.75 \mathrm{mg} / \mathrm{kg}$ per day) for 10-17 days, and cats in which hypothyroidism had been induced by a single intraperitoneal injection of $1 \mathrm{mCi} / \mathrm{kg}$ ${ }^{131}$ I 116-160 days before study. The animals were anesthetized with intraperitoneal pentobarbital $(25 \mathrm{mg} / \mathrm{kg})$, and blood was obtained for determination of serum proteinbound iodine and cholesterol. The hearts were then removed, and right ventricular papillary muscles were rapidly excised and transferred to a myograph containing a Krebs-bicarbonate solution ( $\mathrm{pH} 7.4$ ) aerated with a mixture of $95 \% \mathrm{O}_{2}$ $5 \% \mathrm{CO}_{2}$ at a constant temperature of $26^{\circ} \mathrm{C} \mathrm{(3).} \mathrm{The} \mathrm{base}$ of each muscle was held in a spring-loaded plastic clip while the upper tendinous end was fastened to an isometric force transducer ${ }^{1}$ by a short length of braided silk suture. Muscles were stimulated ${ }^{2}$ directly by stainless steel wires on the inner surface of the attachment clip. Square wave impulses of $5 \mathrm{msec}$ duration and a voltage of $10 \%$ above threshold were employed.

Tension and the stimulus artifact were recorded at a paper speed of $100 \mathrm{~mm} / \mathrm{sec}$ on a multichannel oscillographic recorder. ${ }^{3}$ Resting and active tension, rate of tension development, and time-to-peak tension were determined from these recordings. The maximal rate of tension development (dT/ $\mathrm{dt}$ ) measured at the peak of the length-active tension curve, $\mathrm{L}_{\max }$, was used as an index of myocardial contractile state for comparing muscle function in the three muscle groups. This parameter has been shown to have a direct relation to the intensity of muscle active state as determined by the quick release method (6). In order to compare the mechanical function of papillary muscles of different sizes, tension was expressed in grams per square millimeter. The cross-sectional area of each muscle was calculated by dividing its wet weight $(\mathrm{mg})$ by its length $(\mathrm{mm})$ assuming the muscle to be cylindrical with a density of 1.0. Mean cross-sectional area was similar in muscles obtained from euthyroid (1.39 $\left.\pm 0.04 \mathrm{~mm}^{2}\right)$ and hyperthyroid cats $\left(1.41 \pm 0.04 \mathrm{~mm}^{2}\right)$ but was somewhat smaller in muscles from the hypothyroid animals $\left(1.19 \pm 0.06 \mathrm{~mm}^{2}, P<0.05\right)$.

Glycolysis was inhibited in all muscles by exposure to $5 \times 10^{-4} \mathrm{M}$ iodoacetic acid for $30 \mathrm{~min}$. The adequacy of this blockade has been demonstrated previously (3). Inhibition of aerobic metabolism was achieved by bathing the muscles in Krebs solution previously equilibrated with $95 \% \mathrm{~N}_{2}-5 \%$ $\mathrm{CO}_{2}$. After each experiment the muscle was rapidly frozen

${ }^{1}$ Model FTA 100; Sanborn Div. of Hewlett-Packard, Waltham, Mass.

${ }^{2}$ Model 104A; American Electronic Laboratories, Inc., Lansdale, $\mathrm{Pa}$.

${ }^{3}$ Model 150; Sanborn Div. of Hewlett-Packard. 
by replacing the muscle bath with a beaker of 2-methylbutane (isopentane) previously cooled in liquid nitrogen to from -150 to $-160^{\circ} \mathrm{C}$. This procedure froze the muscle without further contraction.

Experimental design. The initial portion of the experiment was similar for all muscles studied. Each muscle was stimulated to contract isometrically at a frequency of $12 / \mathrm{min}$ for $30 \mathrm{~min}$ with a resting tension of approximately $0.1 \mathrm{~g}$. Its length-active tension curve was then determined, and the muscle was stimulated to contract at the apex of this curve for an additional $30 \mathrm{~min}$. Stimulation was then terminated and iodoacetic acid added to the bath. After the muscle had remained in this solution for $30 \mathrm{~min}$ without resting tension, the bath was abruptly drained, flushed with $95 \% \quad \mathrm{~N}_{2}-5 \%$ $\mathrm{CO}_{2}$, and refilled with Krebs solution previously equilibrated with this gas mixture.

To determine the energy utilization of resting muscle, 86 muscles from euthyroid, 45 muscles from hyperthyroid, and 17 muscles from hypothyroid cats, left unstimulated at zero resting tension, were frozen either immediately after the change to the nitrogenated solution or after $3-, 7-$, or $10-$ min periods of nitrogenation. Data on resting energy utilization of 76 muscles from the euthyroid cats included in this study have been reported previously (4).

The energy cost of isometric contraction was determined in 16 muscles from hypothyroid cats, 28 muscles from euthyroid animals, and 35 muscles from hyperthyroid cats. After $3 \mathrm{~min}$ of rest in the nitrogenated Krebs solution, muscles were stretched to that resting tension, which had been found at the apex of their previously determined lengthactive tension curves, and were stimulated to contract isometrically 25 times at a frequency of $30 / \mathrm{min}$ before freezing.

Chemical analysis. Frozen muscles were stored in liquid nitrogen. At the time of analysis each muscle was reduced to powder at $-50^{\circ} \mathrm{C}(7)$, and after addition of $0.3 \mathrm{M}$ perchloric acid, was allowed to thaw and extract for $10 \mathrm{~min}$ at $0^{\circ} \mathrm{C}$. Creatine phosphate, inorganic phosphate, ATP, and creatine contents were determined on aliquots of the supernatant following centrifugation at $25,000 \mathrm{~g}$ for $10 \mathrm{~min}$ at $0^{\circ} \mathrm{C}$. Total creatine was determined by the $\alpha$-naphthol-diacetyl method $(8,9)$. Creatine phosphate and inorganic phosphate contents were determined by the Furchgott and deGubareff (10) modification of the Fiske and SubbaRow (11) technique. ATP was assayed by a modification of the firefly luminescence technique of Strehler and McElroy (12) using firefly lantern extract."

To avoid possible errors from weighing small samples in the frozen state, muscle weights were calculated from the creatine content of the muscle sample using creatine concentrations measured in two separately obtained right ventricular samples from the same heart. The validity of this method was confirmed in a previous study (3) in which it was shown that the creatine concentration of papillary muscles was similar to that of adjacent right ventricular natecle. Muscles weighing less than $5 \mathrm{mg}$ or more than 15 mg were discarded.

Calculations. Calculations of contractile element work $(\mathrm{CEW})$, i.e. the work performed by the contractile element in stretching the series elastic component, were made from the formula $\mathrm{CEW}=\mathrm{f} / \mathrm{k}$ where $\mathrm{f}$ equals the summated total active tension in grams per square centimeter generated by each muscle during the experimental period, and $\mathrm{k}$ is the series elastic constant previously derived (13) from the relation of the modulus of elasticity of the series elastic $(\mathrm{df} / \mathrm{dl})$ to load, $\mathrm{f}: \mathrm{df} / \mathrm{dl}=\mathrm{k} \cdot \mathrm{f}$. It has been demonstrated

\footnotetext{
4 Sigma Chemical Co., St. Louis, Mo.
}

previously that the constant of the series elastic component is not altered by changes in thyroid state (14).

The basal rate of energy utilization in the resting muscles was calculated by a linear regression on time with total high-energy phosphate concentration $(\sim \mathrm{P}=\mathrm{ATP}+$ creatine phosphate) as the dependent variable. In addition total energy utilization $(\Delta \sim P)$ was calculated for each muscle which had been contracted 25 times. Muscle content of ATP (ATPc), creatine phosphate $(\mathrm{CPc})$, and creatine (creatine $)$ was directly assessed in each muscle. It was not possible to measure directly the high-energy phosphates present in any given muscle both before and after stimulation, since one muscle could not be sampled twice. Thus, the initial highenergy phosphate contents in each active muscle were estimated from the average values obtained in muscles from the same treatment group after $3 \mathrm{~min}$ of rest during the period of metabolic blockade. Both initial and final highenergy phosphate contents were expressed as the quotient of

$$
\frac{\mathrm{ATPc}_{\mathrm{T}} \mathrm{CPc}}{\text { creatine }_{\mathrm{c}}}
$$

with creatine serving as an index of tissue extraction. The result obtained by subtracting the final quotient from the estimated initial quotient represents the utilization of ATP and creatine phosphate in each muscle in terms of directly assessed contents. This value was converted into the concentration of high-energy phosphate used $(\Delta \sim \mathrm{P})$ by multiplying it by the creatine concentration of the adjacent right ventricle which has been shown to be similar to that found in the papillary muscle (3).

All values are expressed as the mean \pm SE. Statistical tests of significance were performed by the $t$ test of the difference between group means (15). Differences between the groups were considered significant when $P<0.05$.

\section{RESULTS}

Characterization of thyroid state. Induction of the hyperthyroid state caused an increase in the serum protein-bound iodine and a decrease in serum cholesterol. The hypothyroid cats had a decreased serum proteinbound iodine and an increased serum cholesterol (Table I). Each of these changes was statistically significant when compared with the euthyroid group. The hyperthyroid cats lost $750 \pm 30 \mathrm{~g}$ body weight during the period of 1-thyroxine administration, whereas the hypothyroid cats gained $100 \pm 50 \mathrm{~g}$ body weight after ${ }^{181} \mathrm{I}$ treatment. The rapid weight loss observed in the hyper-

TABLE I

Characterization of Thyroid State

\begin{tabular}{lccccc}
\hline & Hypothyroid & Euthyroid & Hyperthyroid \\
\hline Serum PBI $(\mu g / 100 m l)$ & $2.0 \pm 0.3^{*}$ & $5.8 \pm 0.1$ & $>20^{*}$ \\
$\begin{array}{l}\text { Serum cholesterol } \\
\quad(\mathrm{mg} / 100 \mathrm{ml})\end{array}$ & $86 \pm 7^{*}$ & $68 \quad \pm 3$ & 54 & $\pm 3^{*}$ \\
Initial body weight $(\mathrm{kg})$ & $3.11 \pm 0.25$ & $2.65 \pm 0.09$ & $3.14 \pm 0.20$ \\
Ventricular weight $(\mathrm{g})$ & $6.44 \pm 0.36$ & $6.68 \pm 0.33$ & $7.63 \pm 0.30$ \\
$\frac{\text { Ventricular weight }(\mathrm{g})}{\text { Initial body weight }(\mathrm{kg})}$ & $2.07 \pm 0.12^{*}$ & $2.52 \pm 0.06$ & $2.43 \pm 0.04$
\end{tabular}

$* P<0.05$ when compared with euthyroid. 
thyroid animals suggests that a marked degree of hyperthyroidism was induced in these cats. A major portion of this weight loss was accounted for by loss of body fat since little subcutaneous or visceral fat was present in the hyperthyroid animals at postmortem examination. The hearts and papillary muscles from the hyperthyroid animals did not appear to be hypertrophied on gross examination. Ventricular weights were similar in the three groups. Due to the rapid loss of body weight in the hyperthyroid cats, ventricular weight was compared with initial body weight to obtain an estimate of relative ventricular size for each experimental group. When compared in this manner, the hearts from the hypothyroid cats were found to be relatively smaller than those from the other two groups (Table I) while hearts from hyperthyroid cats did not differ from normal.

Myocardial mechanics. During metabolic blockade, muscles from each group were stimulated to contract 25 times at a frequency of $30 / \mathrm{min}$ before freezing. There was no evidence of contracture in any of the muscles during the contraction period. Resting tension at $L_{\max }$ was similar in the three muscle groups averaging 1.2 $\pm 0.2,1.1 \pm 0.2$, and $1.1 \pm 0.1 \mathrm{~g} / \mathrm{mm}^{2}$ in the hypothyroid, euthyroid, and hyperthyroid groups respectively. Peak active tension and rate of tension development were attained after $15 \pm 0.8$ contractions in the muscles from the hyperthyroid cats, whereas the euthyroid group required $20 \pm 1.0$ contractions and the hypothyroid $23 \pm 1.0$ contractions. Once attained, peak tension and rate of tension development remained essentially unchanged in each muscle until the 25 contractions were concluded, and the muscle was frozen. Peak isometric contractile function in the three muscle groups is compared in Fig. 2. The rate of tension development (dT/dt) was greater in muscles from hyperthyroid than euthyroid cats although the differences were not statistically significant. Time-to-peak tension and developed tension were significantly less in the hyperthyroid group. Developed tension and $\mathrm{dT} / \mathrm{dt}$ were significantly less, and time-to-peak tension significantly greater in muscles from the hypothyroid group than in muscles from euthyroid animals.

Total contractile element work performed during the 25 isometric contractions in muscles from euthyroid cats $(371 \pm 20 \mathrm{~g}-\mathrm{cm} / \mathrm{g})$ was similar to that in muscles from hyperthyroid cats $(370 \pm 25 \mathrm{~g}-\mathrm{cm} / \mathrm{g})$ while muscles in the hypothyroid group performed significantly less work $(301 \pm 23 \mathrm{~g}-\mathrm{cm} / \mathrm{g}, P<0.05)$.

$\Sigma \mathrm{dT} / \mathrm{dt}$ for the 25 contractions was averaged in each muscle group to provide an estimate of contractile state during the contraction period. $\Sigma \mathrm{dT} / \mathrm{dt}$ was somewhat greater in the hyperthyroid group $\left(590 \pm 35 \mathrm{~g} / \mathrm{mm}^{2}\right.$ per sec, $0.10>P>0.05$ ) and significantly less in the hypothyroid cats $\left(331 \pm 41 \mathrm{~g} / \mathrm{mm}^{2}\right.$ per sec, $\left.P<0.05\right)$ than in the euthyroid animals $\left(515 \pm 31 \mathrm{~g} / \mathrm{mm}^{2}\right.$ per $\left.\mathrm{sec}\right)$.

Resting energy utilization. Initial high-energy phosphate stores were similar in papillary muscles from euthyroid and hyperthyroid cats (16.6 \pm 0.7 vs. 16.4 $\pm 0.6 \mu$ moles $/ g$ ), whereas stores in muscles from hypothyroid cats were somewhat lower $(14.2 \pm 0.6 \mu \mathrm{moles} / \mathrm{g}$, $0.10>P>0.05)$. A regression analysis of total energy stores with time (Fig. 3) indicated that the resting rate of energy utilization tended to be elevated in muscles from hyperthyroid animals ( $1.00 \pm 0.09 \mu$ moles/ $g$ per $\mathrm{min}$ ) compared with the rate in muscles from euthyroid animals $(0.78 \pm 0.07 \mu$ moles $/ g$ per min, 0.10 $>P>0.05)$, whereas the rate was significantly and
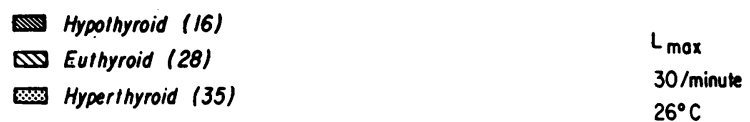

$26^{\circ} \mathrm{C}$

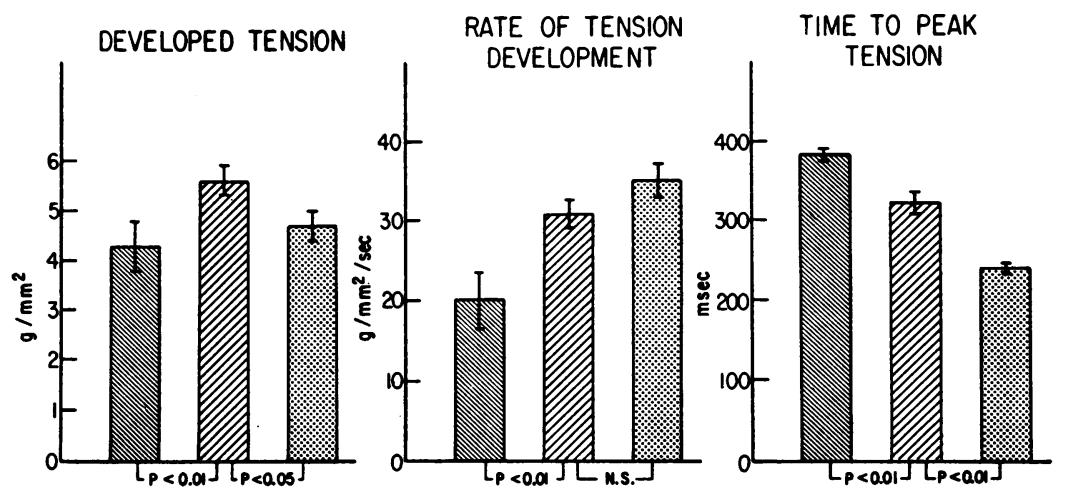

FIGURE 2 Isometric contractile function analyzed as a function of level of thyroid state. Measurements made at contraction frequency of $30 / \mathrm{min}$ at apex of length-active tension curve, $\mathrm{L}_{\max }$, during period of metabolic blockade. NS $=P>0.05$. 


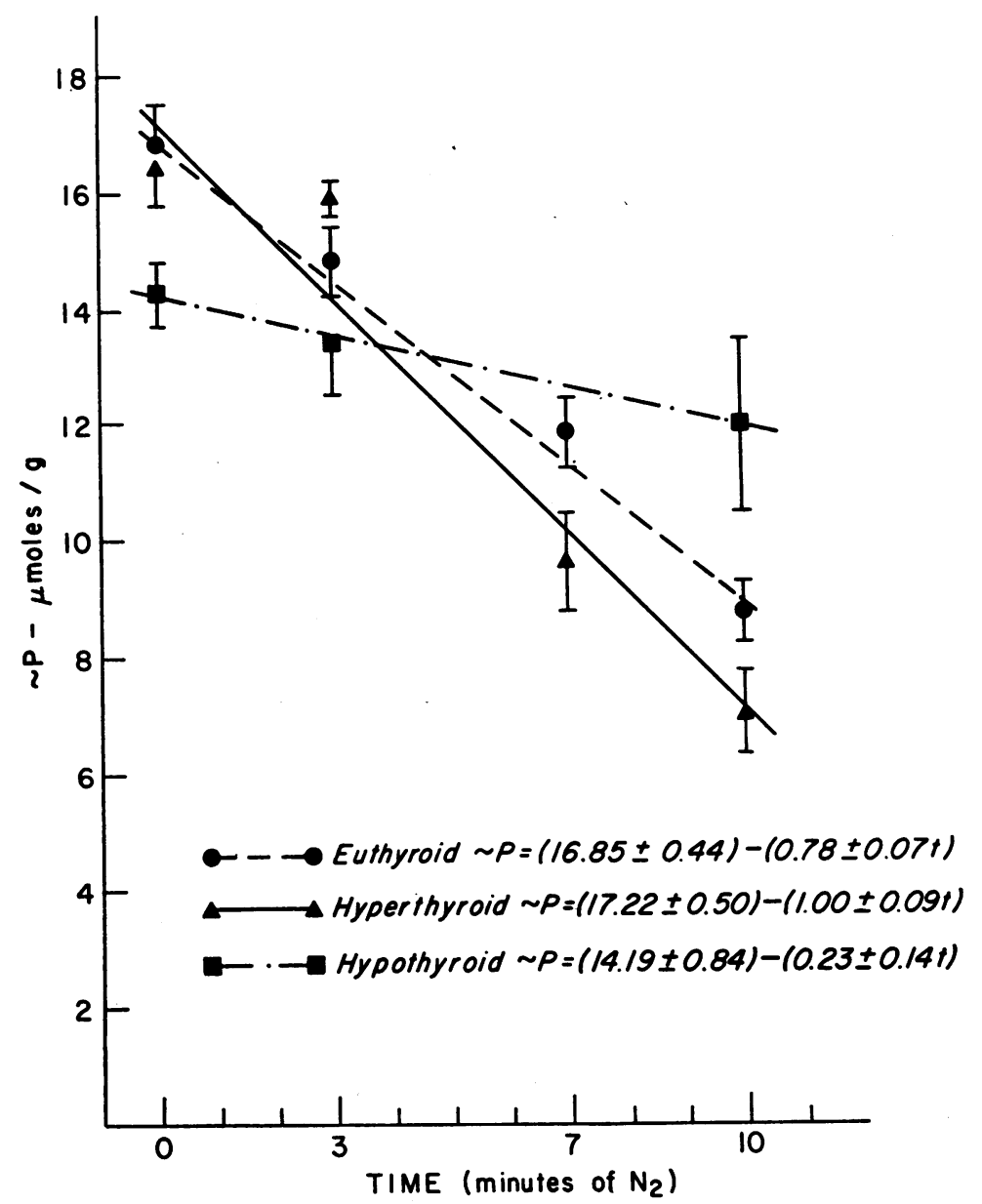

FIGURE 3 Resting energy utilization in papillary muscles from euthyroid, hyperthyroid, and hypothyroid cats as determined by regression analysis. $\sim \mathrm{P}=$ sum of creatine phosphate and ATP. $\mathrm{t}=$ time in minutes of nitrogenation. Mean $\sim \mathrm{P} \pm \mathrm{SE}$ is plotted at $0,3,7$, and $10 \mathrm{~min}$ of nitrogenation.

markedly depressed in muscles from hypothyroid cats $(0.23 \pm 0.14 \mu$ moles $/ g$ per min, $P<0.01)$.

Energy utilization of isometric contractions. The measured content of ATP, creatine phosphate, and creatine in each muscle frozen after 25 contractions is shown in Table II. The initial high-energy phosphate content in each active muscle was estimated from the average value found in muscles from the same experimental group frozen after $3 \mathrm{~min}$ of rest. The total energy utilized in the active muscles was then determined by subtracting the final high-energy phosphate stores from the estimated initial stores. This average total energy utilization was $2.36 \pm 0.56,4.07 \pm 0.33$, and $5.64 \pm 0.34$ $\mu$ moles $/ \mathrm{g}$, respectively, in muscles from hypothyroid, euthyroid, and hyperthyroid animals. These values for the hypothyroid and hyperthyroid groups differed significantly from that of the euthyroid cats $(P<0.01)$.
The average amount of energy used per muscle for activation and the performance of work was obtained by subtracting resting energy utilization during the $50 \mathrm{sec}$ contraction period from the total energy used (Fig. 4). Average active energy utilization was greater in the hyperthyroid group $(4.81 \mu$ moles $/ g)$ and less in the hypothyroid muscles $(2.18 \mu$ moles $/ g)$ as compared with the euthyroid group ( $3: 42 \mu$ moles $/ g$ ).

Comparative average values for muscle mechanics and active energy utilization are depicted in Table III. Muscles from hypothyroid animals utilized an average of only $64 \%$ as much energy as muscles from euthyroid cats while performing $81 \%$ as much work at a moderately decreased level of contractile state. Muscles from hyperthyroid cats utilized an average of $41 \%$ more energy than did muscles from euthyroid cats while per- 
TABLE II

Summary of Biochemical Data

\begin{tabular}{|c|c|c|c|c|c|c|c|}
\hline $\begin{array}{l}\text { Experi- } \\
\text { ment } \\
\text { no. }\end{array}$ & $\begin{array}{c}\text { ATP } \\
\text { content }\end{array}$ & $\begin{array}{c}\mathrm{CP} \\
\text { content }\end{array}$ & $\begin{array}{l}\text { Creatine } \\
\text { content }\end{array}$ & $\frac{\text { ATPc }+\mathrm{CPC}_{\mathrm{c}}}{\text { Creatine }_{\mathrm{o}}}$ & $\frac{\Delta \sim \mathrm{Pc}_{\mathrm{c}}}{\text { Creatine }_{\mathrm{e}}}$ & $\begin{array}{l}\text { Creatine } \\
\text { concen- } \\
\text { tration }\end{array}$ & $\begin{array}{r}\text { Total } \\
\Delta \sim \mathrm{P}\end{array}$ \\
\hline & umoles & umoles & umoles & & & 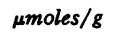 & $\mu$ moles $/ \mathrm{g}$ \\
\hline \multicolumn{8}{|c|}{ Hypothyroid } \\
\hline 1 & 0.073 & 0.127 & 0.219 & 0.913 & 0.091 & 16.0 & 1.46 \\
\hline 2 & 0.034 & 0.076 & 0.152 & 0.724 & 0.280 & 20.9 & 5.85 \\
\hline 3 & 0.025 & 0.035 & 0.090 & 0.667 & 0.337 & 16.9 & 4.99 \\
\hline 4 & 0.062 & 0.065 & 0.142 & 0.894 & 0.110 & 12.3 & 1.35 \\
\hline 5 & 0.051 & 0.068 & 0.144 & 0.826 & 0.178 & 16.9 & 3.01 \\
\hline 6 & 0.075 & 0.126 & 0.260 & 0.773 & 0.231 & 16.8 & 3.88 \\
\hline 7 & 0.037 & 0.066 & 0.127 & 0.811 & 0.193 & 15.9 & 3.07 \\
\hline 8 & 0.045 & 0.083 & 0.174 & 0.736 & 0.268 & 15.7 & 4.21 \\
\hline 9 & 0.027 & 0.078 & 0.139 & 0.755 & 0.249 & 16.0 & 3.98 \\
\hline 10 & 0.025 & 0.052 & 0.099 & 0.778 & 0.226 & 15.4 & 3.48 \\
\hline 11 & 0.033 & 0.051 & 0.092 & 1.022 & -0.018 & 13.2 & -0.24 \\
\hline 12 & 0.044 & 0.063 & 0.110 & 0.973 & 0.031 & 14.8 & 0.46 \\
\hline 13 & 0.040 & 0.048 & 0.106 & 0.830 & 0.174 & 16.3 & 2.84 \\
\hline 14 & 0.030 & 0.064 & 0.089 & 1.056 & -0.052 & 15.2 & -0.79 \\
\hline 15 & 0.039 & 0.070 & 0.100 & 1.090 & -0.086 & 9.5 & -0.82 \\
\hline 16 & 0.028 & 0.038 & 0.068 & 0.971 & 0.033 & 12.0 & 0.40 \\
\hline Mean & $0.042^{*}$ & 0.069 & 0.132 & 0.864 & $0.140 \ddagger$ & 15.2 & $2.36 \ddagger$ \\
\hline SE & 0.004 & 0.007 & 0.013 & 0.265 & 0.033 & 0.7 & 0.56 \\
\hline \multicolumn{8}{|l|}{ Euthyroid } \\
\hline 1 & 0.051 & 0.067 & 0.162 & 0.728 & 0.300 & 17.0 & 5.10 \\
\hline 2 & 0.040 & 0.027 & 0.085 & 0.788 & 0.240 & 15.2 & 3.65 \\
\hline 3 & 0.039 & 0.036 & 0.099 & 0.758 & 0.270 & 17.3 & 4.67 \\
\hline 4 & 0.053 & 0.070 & 0.147 & 0.837 & 0.191 & 16.0 & 3.06 \\
\hline 5 & 0.041 & 0.059 & 0.103 & 0.971 & 0.057 & 14.4 & 0.82 \\
\hline 6 & 0.048 & 0.067 & 0.149 & 0.772 & 0.256 & 19.9 & 5.09 \\
\hline 7 & 0.078 & 0.112 & 0.242 & 0.785 & 0.243 & 18.8 & 4.57 \\
\hline 8 & 0.041 & 0.041 & 0.100 & 0.820 & 0.208 & 19.4 & 4.04 \\
\hline 9 & 0.039 & 0.043 & 0.101 & 0.812 & 0.216 & 12.0 & 2.59 \\
\hline 10 & 0.033 & 0.036 & 0.088 & 0.784 & 0.244 & 16.7 & 4.07 \\
\hline 11 & 0.050 & 0.055 & 0.130 & 0.808 & 0.220 & 15.4 & 3.39 \\
\hline 12 & 0.054 & 0.090 & 0.166 & 0.867 & 0.161 & 13.7 & 2.21 \\
\hline 13 & 0.041 & 0.033 & 0.090 & 0.822 & 0.206 & 12.8 & 2.64 \\
\hline 14 & 0.063 & 0.060 & 0.150 & 0.820 & 0.208 & 11.2 & 2.33 \\
\hline 15 & 0.034 & 0.040 & 0.099 & 0.747 & 0.281 & 16.5 & 4.64 \\
\hline 16 & 0.045 & 0.054 & 0.138 & 0.717 & 0.311 & 16.4 & 5.10 \\
\hline 17 & 0.050 & 0.073 & 0.176 & 0.699 & 0.329 & 19.8 & 6.51 \\
\hline 18 & 0.047 & 0.047 & 0.110 & 0.855 & 0.173 & 18.0 & 3.11 \\
\hline 19 & 0.068 & 0.065 & 0.158 & 0.842 & 0.186 & 17.2 & 3.20 \\
\hline 20 & 0.084 & 0.107 & 0.278 & 0.687 & 0.341 & 20.0 & 6.82 \\
\hline 21 & 0.058 & 0.083 & 0.188 & 0.750 & 0.278 & 17.9 & 4.98 \\
\hline 22 & 0.044 & 0.062 & 0.118 & 0.898 & 0.130 & 14.2 & 1.85 \\
\hline 23 & 0.074 & 0.141 & 0.309 & 0.696 & 0.332 & 22.1 & 7.34 \\
\hline 24 & 0.033 & 0.051 & 0.108 & 0.778 & 0.250 & 15.4 & 3.85 \\
\hline 25 & 0.066 & 0.067 & 0.162 & 0.821 & 0.207 & 15.8 & 3.27 \\
\hline 26 & 0.041 & 0.052 & 0.155 & 0.600 & 0.428 & 19.8 & 8.47 \\
\hline 27 & 0.048 & 0.065 & 0.141 & 0.801 & 0.227 & 15.8 & 3.59 \\
\hline 28 & 0.059 & 0.058 & 0.142 & 0.824 & 0.204 & 14.6 & 2.98 \\
\hline Mean & 0.051 & 0.063 & 0.146 & 0.789 & 0.239 & 16.5 & 4.07 \\
\hline SE & 0.002 & 0.005 & 0.011 & 0.014 & 0.014 & 0.5 & 0.33 \\
\hline
\end{tabular}


TABLE II-(Continued)

\begin{tabular}{|c|c|c|c|c|c|c|c|}
\hline $\begin{array}{c}\text { Experi- } \\
\text { ment } \\
\text { no. }\end{array}$ & $\begin{array}{c}\text { ATP } \\
\text { content }\end{array}$ & $\begin{array}{c}\mathrm{CP} \\
\text { content }\end{array}$ & $\begin{array}{c}\text { Creatine } \\
\text { content }\end{array}$ & $\frac{\mathrm{ATPc}+\mathrm{CPc}}{\text { Creatine }_{\mathrm{c}}}$ & $\frac{\Delta \sim \mathrm{Pc}_{\mathrm{c}}}{\text { Creatineo }}$ & $\begin{array}{c}\text { Creatine } \\
\text { concen- } \\
\text { tration }\end{array}$ & $\begin{array}{c}\text { Total } \\
\Delta \sim \mathrm{P} \\
\end{array}$ \\
\hline & umoles & 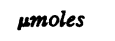 & umoles & & & umoles $/ \mathrm{g}$ & $\mu$ moles $/ \mathrm{g}$ \\
\hline \multicolumn{8}{|c|}{ Hyperthyroid } \\
\hline 1 & 0.058 & 0.062 & 0.140 & 0.857 & 0.290 & 14.2 & 4.12 \\
\hline 2 & 0.071 & 0.080 & 0.195 & 0.774 & 0.373 & 16.5 & 6.15 \\
\hline 3 & 0.055 & 0.030 & 0.112 & 0.759 & 0.388 & 13.8 & 5.35 \\
\hline 4 & 0.055 & 0.055 & 0.151 & 0.728 & 0.419 & 13.4 & 5.61 \\
\hline 5 & 0.046 & 0.049 & 0.104 & 0.913 & 0.234 & 13.0 & 3.04 \\
\hline 6 & 0.058 & 0.062 & 0.160 & 0.750 & 0.397 & 14.4 & 5.72 \\
\hline 7 & 0.051 & 0.097 & 0.163 & 0.908 & 0.239 & 14.2 & 3.39 \\
\hline 8 & 0.045 & 0.031 & 0.098 & 0.776 & 0.371 & 15.1 & 5.60 \\
\hline 9 & 0.077 & 0.075 & 0.187 & 0.813 & 0.334 & 12.8 & 4.28 \\
\hline 10 & 0.045 & 0.029 & 0.124 & 0.597 & 0.550 & 15.8 & 8.69 \\
\hline 11 & 0.047 & 0.042 & 0.109 & 0.817 & 0.330 & 13.2 & 4.36 \\
\hline 12 & 0.059 & 0.063 & 0.146 & 0.836 & 0.311 & 12.2 & 3.79 \\
\hline 13 & 0.052 & 0.070 & 0.153 & 0.797 & 0.350 & 14.4 & 5.04 \\
\hline 14 & 0.046 & 0.027 & 0.091 & 0.802 & 0.345 & 11.4 & 3.93 \\
\hline 15 & 0.038 & 0.033 & 0.077 & 0.922 & 0.225 & 11.8 & 2.66 \\
\hline 16 & 0.042 & 0.042 & 0.114 & 0.737 & 0.410 & 14.5 & 5.95 \\
\hline 17 & 0.030 & 0.008 & 0.095 & 0.400 & 0.747 & 14.8 & 11.06 \\
\hline 18 & 0.065 & 0.063 & 0.168 & 0.762 & 0.385 & 12.9 & 4.97 \\
\hline 19 & 0.040 & 0.017 & 0.110 & 0.518 & 0.629 & 15.0 & 9.44 \\
\hline 20 & 0.052 & 0.030 & 0.113 & 0.726 & 0.421 & 13.4 & 5.64 \\
\hline 21 & 0.094 & 0.152 & 0.330 & 0.745 & 0.402 & 23.9 & 9.61 \\
\hline 22 & 0.033 & 0.025 & 0.079 & 0.734 & 0.413 & 14.6 & 6.03 \\
\hline 23 & 0.050 & 0.028 & 0.113 & 0.690 & 0.457 & 14.6 & 6.67 \\
\hline 24 & 0.082 & 0.091 & 0.190 & 0.911 & 0.236 & 16.4 & 3.87 \\
\hline 25 & 0.054 & 0.068 & 0.150 & 0.813 & 0.334 & 17.4 & 5.81 \\
\hline 26 & 0.068 & 0.068 & 0.171 & 0.795 & 0.352 & 16.4 & 5.77 \\
\hline 27 & 0.069 & 0.060 & 0.183 & 0.705 & 0.442 & 12.4 & 5.48 \\
\hline 28 & 0.056 & 0.048 & 0.171 & 0.608 & 0.539 & 12.5 & 6.74 \\
\hline 29 & 0.049 & 0.043 & 0.106 & 0.868 & 0.279 & 14.3 & 3.99 \\
\hline 30 & 0.033 & 0.040 & 0.096 & 0.760 & 0.387 & 14.3 & 5.53 \\
\hline 31 & 0.051 & 0.041 & 0.154 & 0.597 & 0.550 & 15.1 & 8.31 \\
\hline 32 & 0.035 & 0.030 & 0.077 & 0.844 & 0.303 & 13.9 & 4.21 \\
\hline 33 & 0.032 & 0.037 & 0.075 & 0.920 & 0.227 & 13.7 & 3.11 \\
\hline 34 & 0.047 & 0.038 & 0.134 & 0.634 & 0.513 & 14.9 & 7.64 \\
\hline 35 & 0.040 & 0.020 & 0.088 & 0.682 & 0.465 & 12.8 & 5.95 \\
\hline Mean & 0.052 & $0.050^{*}$ & 0.135 & 0.757 & $0.390 \ddagger$ & $14.4 \ddagger$ & $5.64 \ddagger$ \\
\hline SE & 0.003 & 0.005 & 0.008 & 0.020 & 0.020 & 0.4 & 0.34 \\
\hline
\end{tabular}

The change in the ratio of total high-energy phosphate content to creatine content $\left(\Delta \sim \mathrm{Pc} /\right.$ creatine $_{\mathrm{c}}$ ) which occurred during the series of isometric contractions was determined for each muscle by subtracting the quotient of the assessed contents $\frac{\mathrm{ATPc}_{\mathrm{T}}+\mathrm{CPc}}{\text { creatine }_{\mathrm{c}}}$ found at the end of the experiment from the average assessed value of this quotient for each group at the beginning of the isometric contraction phase of the experiment $(1.004,1.028$, and 1.147 for the hypothyroid, euthyroid, and hyperthyroid groups, respectively). High-energy phosphate utilization $(\Delta \sim \mathrm{P})$ was then determined by multiplying $\Delta \sim \mathrm{Pc}_{\mathrm{c}}$ creatine by $_{\mathrm{o}}$ the creatine concentration of the adjacent right ventricle. $\mathrm{CP}=$ creatine phosphate.

${ }^{*} P<0.05$ when compared with euthyroid.

$\ddagger P<0.01$ when compared with euthyroid. 


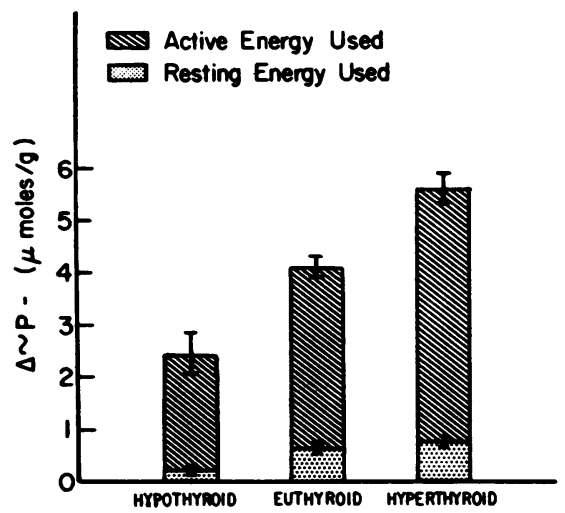

FIgUre 4 Total energy utilization in papillary muscles from euthyroid, hypothyroid, and hyperthyroid cats during isometric contraction. Total energy utilization = sum of active energy used and resting energy used. $\Delta \sim \mathrm{P}=$ utilization of creatine phosphate and ATP.

forming an equal amount of contractile element work at a slightly increased level of contractile state.

\section{DISCUSSION}

The purpose of the present study was to determine whether or not the rate or efficiency of energy utilization is changed in cardiac muscle by alterations in thyroid state. It was observed that the resting rate of energy utilization was increased in muscles from hyperthyroid cats and decreased in those from hypothyroid cats. Under conditions where the frequency and number of isometric contractions were identical, muscles from hyperthyroid cats utilized an average of $41 \%$ more chemical energy than did muscles from euthyroid animals, whereas muscles from hypothyroid cats used $36 \%$ less. These results were obtained under conditions which measured only energy utilization. Therefore, changes in intermediary metabolism affecting energy generation and conservation, such as uncoupling of oxidative phosphorylation, could not be responsible for the demonstrated changes in energy utilization.
Myocardial energy requirements during isometric contraction are largely determined by the mechanical behavior of the muscle. Tension development and contractile state have been identified as the most important determinants of myocardial energy needs $(16,17)$. Contractile element work, a linear function of active tension, was nearly identical in the muscles from the hyperthyroid and euthyroid cats, whereas $\mathrm{dT} / \mathrm{dt}$, an estimate of myocardial contractile state, was $14 \%$ greater in the muscles from the hyperthyroid group. This increase in $\mathrm{dT} / \mathrm{dt}$ in hyperthyroidism probably contributed to the increased energy requirements of muscles in the hyperthyroid group. In a previous study attempting to define the relative role of contractile state in determining myocardial oxygen consumption, it was found that a $43 \%$ increase in contractile state, measured as $\mathrm{V}_{\max }$, was associated with a $50 \%$ increase in oxygen consumption (18). Thus, it seems unlikely that the small increase in myocardial contractile state noted in hyperthyroidism in the present study could entirely account for the large increase in energy utilization measured in this condition. Rather, our results suggest that the increased energy utilization of contracting cardiac muscle from hyperthyroid cats is attributable to alterations in the conversion of chemical energy to mechanical work, i.e., an inefficient process of energy utilization.

It is possible that alterations of cellular energy utilizing processes in hyperthyroidism not directly related to muscle contraction could account for a portion of the increase in high-energy phosphates used during contraction. Thus, it is possible that an increased amount of energy is required in the hyperthyroid hearts for the process of activating muscle contraction. The design of the present study, however, precluded any attempt to estimate activation-related energy utilization in these muscles. Wang and Benmiloud recently reported that hearts from hyperthyroid rats had an increased adenosine triphosphatase activity in cellular fractions containing mitochondria (19). Similar results have been reported from human skeletal muscle (20). These find-

TABLE III

Comparative Average Values for Muscles from Euthyroid Cats and Cats with Experimental Hypothyroidism and Hyperthyroidism

\begin{tabular}{lccccc}
\hline & Hypothyroid & Euthyroid & Hyperthyroid & $\frac{\text { Hypothyroid }}{\text { Euthyroid }} \times 100$ & $\frac{\text { Hyperthyroid }}{\text { Euthyroid }} \times 100$ \\
\hline $\begin{array}{l}\text { No. of contractions } \\
\text { Contractile element } \\
\text { work }(\mathrm{g}-\mathrm{cm} / \mathrm{g})\end{array}$ & 25 & 25 & 25 & $100 \%$ & $100 \%$ \\
$\begin{array}{c}\Sigma \mathrm{dT} / \mathrm{dt} \\
\left(\mathrm{g} / \mathrm{mm}^{2} \text { per sec }\right)\end{array}$ & 310 & 371 & 370 & $81 \%$ & $100 \%$ \\
$\begin{array}{c}\text { Active } \sim P \text { used } \\
(\mu \mathrm{moles} / \mathrm{g})\end{array}$ & 2.18 & 3.42 & 4.81 & $64 \%$ & $114 \%$ \\
\hline
\end{tabular}


ings are consistent with the alterations in resting rate of energy utilization found in the muscles from hyperthyroid animals in the present study. However, the increase in the resting rate of energy utilization in hyperthyroid muscles accounts for only $11 \%$ of the increase in total energy utilization observed in these muscles during contraction. Thus, while a portion of the increase in myocardial energy utilization found in hyperthyroidism may be attributed to nonspecific processes occurring continually, the major portion of this increase in energy utilization probably occurs in association with the contractile process.

In contrast to the findings in hyperthyroidism, contracting muscles from hypothyroid cats utilized only $64 \%$ as much chemical energy as those from euthyroid cats while performing $81 \%$ as much contractile element work at a contractile state level reduced by $36 \%$ as estimated by $\mathrm{dT} / \mathrm{dt}$. Although quantification of their individual contributions is not possible, the magnitude of these decreases in contractile element work and contractile state appears sufficient to explain the decreased energy utilization observed in muscles from hypothyroid cats.

Previous attempts to define myocardial efficiency in hyperthyroidism have given conflicting results (21-23). In some instances myocardial efficiency has been thought to be increased $(22,23)$. However, alterations of myocardial efficiency calculated on the basis of minute work output of the heart may be difficult to interpret, especially in states in which the level of thyroid state is altered causing marked changes in cardiac output. Evans and Matsuoka (24) have demonstrated that an increase in cardiac work resulting primarily from an increase in cardiac output was associated with a much smaller increase in oxygen consumption than an increase in cardiac work resulting from increasing aortic pressure. These findings have been repeatedly confirmed and were recently extended to the isolated process of energy utilization (4). Thus, increases in myocardial oxygen consumption in hyperthyroidism which are proportional to the increase in minute work may actually reflect an inefficient process of energy utilization, since an increase in cardiac output in the absence of hyperthyroidism should result in a less than proportional increase in oxygen consumption. More recently, the oxygen consumption of papillary muscles from hyperthyroid cats was found to be greater than that of muscles from euthyroid cats (25). Although consistent with the hypothesis that thyroid hormone reduces the efficiency of energy utilization, these results were obtained under conditions which did not exclude possible alterations in the process of energy generation.

Attempts to characterize myocardial energetics in hypothyroidism have also given conflicting results. Goh and Dallam (26) reported that nonworking ventricular preparations from hypothyroid rats had a decreased oxygen consumption. Myocardial oxygen consumption was found to be decreased in hypothyroid dogs $(27,28)$ but myocardial efficiency was also reported to be decreased (28). In one patient with hypothyroidism secondary to thyroiditis, a normal myocardial oxygen consumption was found (29). The interpretation of these results is limited, however, because none of these studies were performed under conditions allowing adequate control or measurement of the important mechanical determinants of myocardial energy requirements.

In a previous study Buccino, Spann, Pool, Sonnenblick, and Braunwald (30) demonstrated that hyperthyroidism was associated with a shift in the forcevelocity curve upward and to the right and an increase in the maximal rate of isometric tension development (dT/dt) in feline papillary muscles stimulated to contract 12 times per minute, whereas opposite changes were associated with hypothyroidism. From these data it was concluded that myocardial contractile state was increased by hyperthyroidism and decreased by hypothyroidism. However, as with most inotropic influences (31), the augmentation of contractile state in hyperthyroidism was rate dependent. At stimulation frequencies of 30 and 48 per min, no significant differences in $\mathrm{dT} / \mathrm{dt}$ were observed in the muscles from the euthyroid and hyperthyroid groups. The rate dependence of the increased contractility in hyperthyroidism was confirmed by Murayama and Goodkind using atria isolated from hyperthyroid guinea pigs (32). The explanation for the rate dependency of inotropic influences is not known but may be related to an upper mechanical limit on the contractile response $(31,33)$. In the present study a stimulation frequency of $30 / \mathrm{min}$ was purposely selected because this frequency reduced the differences in contractile state between muscles from hypothyroid, euthyroid, and hyperthyroid animals. Under these conditions a direct effect of thyroid hormone on energy utilization could be more readily identified.

The calorigenic action of thyroid hormone could be the result of a fundamental action at several levels of metabolism. First, it could involve the process of energy production and result from an uncoupling of oxidative phosphorylation. Many investigations have been devoted to this aspect of energy metabolism and have yielded varying results. At the present time it appears that uncoupling of oxidative phosphorylation is not produced in vivo with physiologic doses of thyroid hormone (34). In the present investigation in order to focus on energy utilization, the process of energy production was specifically inhibited, and therefore no information relative to energy production is available. Second, abnormally increased energy utilization could be responsible 
for the calorigenic action of thyroid hormone. This increase could involve accelerated basal processes, perhaps not directly related to processes of cellular work, e.g. increased activity of mitochondrial ATPase (19, 20). Some support for this concept was found in the present study in the changes in basal energy utilization of resting heart muscle produced by alterations of thyroid state. Finally, it is also possible that the calorigenic action of thyroid hormone results from a decrease in the efficiency of energy utilization as the level of thyroid state is increased so that the amount of energy used in hyperthyroidism is in excess of that required of euthyroid tissues for performing identical levels of cellular work. The results obtained in contracting muscles from hyperthyroid animals in the present study, support this latter hypothesis. Whereas its calorigenic effect is one of the most characteristic actions of thyroid hormone, it also influences growth and maturation, water and salt metabolism, protein and lipid synthesis and breakdown, bone metabolism, and skeletal muscle function (2). Whether or not the calorigenic effect of thyroid hormone is a fundamental one on which all of the other actions depend is not known. Thus, the possible contribution of inefficient energy utilization to these other actions of thyroid hormone cannot be directly assessed.

The fundamental mechanism by which thyroid hormone alters the utilization of energy by the heart remains to be elucidated. Recent studies of the basic mechanism of action of thyroid hormone have stressed the importance of its effect on protein synthesis (35, 36 ), and it has been postulated that thyroid hormone exerts its characteristic effects by a selective control of the synthesis of enzymes or structural proteins. Applying this concept to heart muscle, it seems possible that thyroid hormone could directly alter the actinmyosin linkages or myosin adenosine triphosphatase in such a way as to control the efficiency of energy utilization. It is also possible that these effects could result from other changes in the contractile proteins or the sarcoplasmic reticulum.

In summary, this investigation has provided evidence that thyroid hormone exerts a profound direct influence on the process of myocardial energy utilization. Both the basal rate of cardiac energy utilization and energy utilization during isometric contraction are increased in hyperthyroidism and decreased in hypothyroidism. The decreased energy utilization in contracting muscles from hypothyroid animals may be largely attributed to decreases in tension generation and contractile state. However, alterations in mechanical behavior of muscles from hyperthyroid cats do not adequately account for the observed increase in cardiac energy utilization, which suggests that the conversion of energy to work is inefficient in these muscles. Thus, alterations in both the rate and efficiency of energy utilization may be important in the control of cellular energy metabolism by thyroid hormone.

\section{ACKNOWLEDGMENTS}

We gratefully acknowledge the skillful technical assistance of Nancy Dittemore. The hypothyroid cats used in this study were prepared by Dr. Jerry F. Stara and Dr. Neal Nelson, Radionuclide Toxicology Laboratory, Division of Radiological Health, U. S. Public Health Service, Cincinnati, Ohio.

This work was supported in part by Grants HE 12010, HE 12373, and 1-K4 HE 23005 from the National Heart and Lung Institute, U. S. Public Health Service.

\section{REFERENCES}

1. Hoch, F. L. 1962. Thyrotoxicosis as a disease of mitochondria. N. Engl. J. Med. 266: 446.

2. Hoch, F. L. 1962. Biochemical actions of thyroid hormones. Physiol. Rev. 42: 605.

3. Pool, P. E., and E. H. Sonnenblick. 1967. The mechanochemistry of cardiac muscle. I. The isometric contraction. J. Gen. Physiol. 50: 951.

4. Pool, P. E., B. M. Chandler, S. C. Seagren, and E. H. Sonnenblick. 1968. Mechanochemistry of cardiac muscle. II. The isotonic contraction. Circ. Res. 22: 465.

5. Cain, D. F., and R. E. Davies. 1962. Breakdown of adenosine triphosphate during a single contraction of working muscle. Biochem. Biophys. Res. Commun. 8: 361.

6. Sonnenblick, E. H. 1967. Active state in heart muscle. Its delayed onset and modification by inotropic agents. J. Gen. Physiol. 50: 661.

7. Pool, P. E., and S. C. Seagren. 1967. Low-temperature extraction of small samples of tissue. Chemist-Analyst. 56: 38.

8. Ennor, A. H., and H. Rosenberg. 1952. The determination and distribution of phosphocreatine in animal tissues. Biochem. J. 51: 606 .

9. Ennor, A. H. 1957. Determination and preparation of $\mathrm{N}$-phosphates of biological origin. In Methods in Enzymology. S. P. Colowick and N. O. Kaplan, editors. Academic Press Inc., New York. 3: 850.

10. Furchgott, R. F., and T. deGubareff. 1956. The determination of inorganic phosphate and creatine phosphate in tissue extracts. J. Biol. Chem. 223: 337.

11. Fiske, C. H., and Y. SubbaRow. 1929. Phosphocreatine. J. Biol. Chem. 81 : 629.

12. Strehler, B. L., and W. D. McElroy. 1957. Assay of adenosine triphosphate. In Methods in Enzymology. S. P. Colowick and N. O. Kaplan, editors. Academic Press Inc., New York. 3: 871.

13. Parmley, W. W., and E. H. Sonnenblick. 1967. Series elasticity in heart muscle. Its relation to contractile element velocity and proposed muscle models. Circ. Res. 20: 112.

14. Parmley, W. W., J. F. Spann, Jr., R. R. Taylor, and E. H. Sonnenblick. 1968. The series elasticity of cardiac muscle in hyperthyroidism, ventricular hypertrophy, and heart failure. Proc. Soc. Exp. Biol. Med. 127: 606.

15. Snedecor, G. W., and W. G. Cochran. 1967. Statistical Methods. Iowa State University Press, Ames, Iowa. 6th edition. 59. 
16. Braunwald, E. 1969. The determinants of myocardial oxygen consumption. Physiologist. 12: 65 .

17. Sonnenblick, E. H., J. Ross, Jr., and E. Braunwald. 1968. Oxygen consumption of the heart. Newer concepts of its multifactoral determination. Amer. J. Cardiol. 22: 328.

18. Graham, T. P., Jr., J. W. Covell, E. H. Sonnenblick, J. Ross, Jr., and E. Braunwald. 1968. Control of myocardial oxygen consumption: relative influence of contractile state and tension development. J. Clin. Invest. 47: 375.

19. Wang, K. M., and M. Benmiloud. 1964. Effect of thyroxine and thiouracil on the $\mathrm{Mg}^{++}$-activated ATPase on the rat myocardium. Life Sci. 3: 431..

20. Stocker, W. W., F. J. Samaha, and L. J. DeGroot. 1968. Coupled oxidative phosphorylation in muscle of thyrotoxic patients. Amer. J. Med. 44: 900.

21. Rowe, G. G., J. H. Huston, A. B. Weinstein, H. Tuchman, J. F. Brown, and C. W. Crumpton. 1956. The hemodynamics of thyrotoxicosis in man with special reference to coronary blood flow and myocardial oxygen metabolism. J. Clin. Invest. 35: 272.

22. Piatnek-Leunissen, D., and R. E. Olson. 1967. Cardiac failure in the dog as a consequence of exogenous hyperthyroidism. Circ. Res. 20: 242.

23. Bing, R. J., M. M. Hammond, J. C. Handelsman, S. R. Powers, F. C. Spencer, J. E. Eickenhoff, W. T. Goodale, J. H. Hafkenschiel, and S. S. Kety. 1949. The measurement of coronary blood flow, oxygen consumption, and efficiency of the left ventricle. Amer. Heart J. 38: 1 .

24. Evans, C. L., and Y. Matsuoka. 1915. The effect of various mechanical conditions on the gaseous metabolism and efficiency of the mammalian heart. J. Physiol. (London). 49: 378.

25. Skelton, C. L., H. N. Coleman, K. Wildenthal, and E. Braunwald. 1970. Augmentation of myocardial oxygen consumption in hyperthyroid cats. Circ. Res. 27: 301.

26. Goh, K., and R. D. Dallam. 1957. Oxygen consumption of the auricles, right and left ventricles of the normal, hypothyroid, and hyperthyroid rat heart. Amer. J. Physiol. 188: 514 .

27. Scott, J. C., T. A. Balourdas, and M. N. Croll. 1961. The effect of experimental hypothyroidism on coronary blood flow and hemodynamic factors. Amer. J. Cardiol. 7: 690 .

28. Gold, M., J. C. Scott, and J. J. Spitzer. 1967. Myocardial metabolism of free fatty acids in control, hyperthyroid, and hypothyroid dogs. Amer. J. Physiol. 213: 239.

29. Den Bakker, P. B., J. F. Sundermeyer, V. E. Wendt, M. Salhaney, S. Gudbjarnason, and R. J. Bing. 1962. Myocardial metabolism in a patient with Hashimoto's thyroiditis and hypothyroidism. Amer. J. Med. $32: 822$.

30. Buccino, R. A., J. F. Spann, Jr., P. E. Pool, E. H. Sonnenblick, and E. Braunwald. 1967. Influence of the thyroid state on the intrinsic contractile properties and energy stores of the myocardium. J. Clin. Invest. 46: 1669.

31. Koch-Weser, J., and J. R. Blinks. 1963. The influence of the interval between beats on myocardial contractility. Pharmacol. Rev. 15: 601.

32. Murayama, M., and J. Goodkind. 1968. Effect of thyroid hormone on the frequency-force relationship of atrial myocardium from the guinea pig. Circ. Res. 23: 743.

33. Sonnenblick, E. H., W. W. Parmley, R. A. Buccino, and J. F. Spann, Jr. 1968. Maximum force development in cardiac muscle. Nature (London). 219: 1056.

34. Tata, J. R. 1964. Basal metabolic rate and thyroid hormones. In Advances in Metabolic Disorders. R. Levine and R. Luft, editors. Academic Press Inc., New York. 1: 153.

35. Tata, J. R., L. Ernster, O. Lindberg, E. Arrhenius, S. Pedersen, and R. Hedman. 1963. The action of thyroid hormones at the cell level. Biochem. J. 86: 408.

36. Tata, J. R. 1967. The formation and distribution of ribosomes during hormone-induced growth and development. Biochem. J. 104: 1. 